\title{
Clinical high risk for psychosis
}

Citation for published version (APA):

van der Steen, Y., Gimpel-Drees, J., Lataster, T., Viechtbauer, W., Simons, C. J. P., Lardinois, M., Michel, T. M., Janssen, B., Bechdolf, A., Wagner, M., \& Myin-Germeys, I. (2017). Clinical high risk for psychosis: the association between momentary stress, affective and psychotic symptoms. Acta Psychiatrica Scandinavica, 136(1), 63-73. https://doi.org/10.1111/acps.12714

Document status and date:

Published: 01/07/2017

DOI:

10.1111/acps.12714

Document Version:

Publisher's PDF, also known as Version of record

Document license:
Taverne

\section{Please check the document version of this publication:}

- A submitted manuscript is the version of the article upon submission and before peer-review. There can be important differences between the submitted version and the official published version of record.

People interested in the research are advised to contact the author for the final version of the publication, or visit the DOI to the publisher's website.

- The final author version and the galley proof are versions of the publication after peer review.

- The final published version features the final layout of the paper including the volume, issue and page numbers.

Link to publication

\footnotetext{
General rights rights.

- You may freely distribute the URL identifying the publication in the public portal. please follow below link for the End User Agreement:

www.umlib.nl/taverne-license

Take down policy

If you believe that this document breaches copyright please contact us at:

repository@maastrichtuniversity.nl

providing details and we will investigate your claim.
}

Copyright and moral rights for the publications made accessible in the public portal are retained by the authors and/or other copyright owners and it is a condition of accessing publications that users recognise and abide by the legal requirements associated with these

- Users may download and print one copy of any publication from the public portal for the purpose of private study or research.

- You may not further distribute the material or use it for any profit-making activity or commercial gain

If the publication is distributed under the terms of Article $25 \mathrm{fa}$ of the Dutch Copyright Act, indicated by the "Taverne" license above, 


\section{Clinical high risk for psychosis: the association between momentary stress, affective and psychotic symptoms}

van der Steen Y, Gimpel-Drees J, Lataster T, Viechtbauer W, Simons CJP, Lardinois M, Michel TM, Janssen B, Bechdolf A, Wagner M, Myin-Germeys I. Clinical high risk for psychosis: the association between momentary stress, affective and psychotic symptoms.

Objective: The aim of this study was to assess associations between momentary stress and both affective and psychotic symptoms in everyday life of individuals at clinical high risk (CHR), compared to chronic psychotic patients and healthy controls, in search for evidence of early stress sensitization. It also assessed whether psychotic experiences were experienced as stressful.

Method: The experience sampling method was used to measure affective and psychotic reactivity to everyday stressful activities, events and social situations in $22 \mathrm{CHR}$ patients, 24 patients with a psychotic disorder and 26 healthy controls.

Results: Multilevel models showed significantly larger associations between negative affect (NA) and activity-related stress for CHR patients than for psychotic patients $(P=0.008)$ and for CHR compared to controls $(P<0.001)$. Similarly, the association between activityrelated stress and psychotic symptoms was larger in CHR than in patients $(P=0.02)$. Finally, the association between NA and symptoms $(P<0.001)$ was larger in CHR than in patients.

Conclusion: Stress sensitization seems to play a role particularly in the early phase of psychosis development as results suggest that CHR patients are more sensitive to daily life stressors than psychotic patients. In this early phase, psychotic experiences also contributed to the experience of stress.

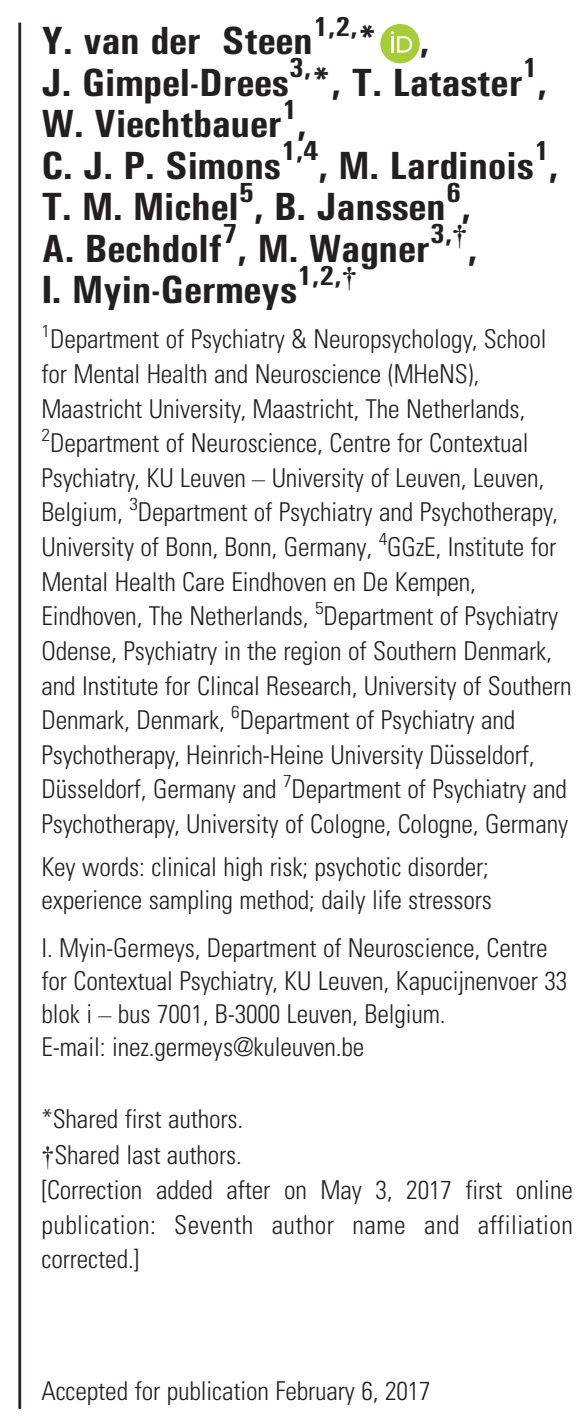

\section{Significant outcomes}

- Momentary emotional and psychotic stress reactivity for unpleasant activities was increased in CHR patients compared to psychotic patients with longer duration of illness.

- Momentary psychotic symptoms are associated with higher levels of negative affect (NA) in the CHR patients than in psychotic patients and may therefore be a stressor in itself.

- Stress sensitization seems to play an important role in psychotic disorder, particularly in the early phase of the illness. 


\section{van der Steen et al.}

\section{Limitations}

- The experience sampling method (ESM) measures of negative affect, psychosis and daily life stress are based on subjective reports.

- The cross-sectional nature of the data precludes definitive conclusions about causation.

- The possible influence of medication use on the examined associations could not be tested as CHR medication use was not yet available.

\section{Introduction}

It has long been suggested that stress plays an important role in the emergence and course of psychotic disorder (1-5). Stressful life events (6), childhood adversity (7), as well as small everyday hassles $(8,9)$ have been associated with the development and course of psychotic disorder. To further elucidate the role of stress in the aetiology of psychotic disorder, attention has shifted to studies of the putative prodromal phase of a psychotic disorder. Participants in such studies are those who experience subclinical psychotic symptoms and meet well established prodromal criteria that describe them to be at 'ultra high risk' (UHR) (10) or 'clinical high risk' (CHR) (11) for a transition to disorder. In this study, the term 'clinical high risk' is utilized.

CHR patients may be more exposed to stressful experiences. Findings regarding the number of life events in CHR patients compared to controls are mixed, with some studies reporting an association between the occurrence of traumatic experiences as well as other negative life events and the expression of subclinical psychotic symptomatology (12-19), while other studies reported no difference in the number of major life events $(20,21)$ or even significantly fewer life events (22). Alternatively, CHR patients may specifically differ in their tolerance of stress. Indeed, life events $(19,22)$, as well as daily life hassles (19), were appraised as significantly more upsetting by CHR patients than controls. Additionally, CHR patients reported impaired tolerance and increased functional impairment in response to normal stress compared to healthy controls (20) and higher self-reported psychosocial stress levels compared to first-episode psychosis patients (23).

Previous studies with the Experience Sampling Method (ESM, a structured diary technique in which subjects are asked in normal daily life to report their thoughts, feelings and symptoms, and also the context (e.g. location, company, activity) and the appraisal of the context, several times per day) have shown a higher emotional and psychotic reactivity to small daily life stressors in psychotic patients, their unaffected relatives and in those at psychometric risk for psychotic disorder when compared to healthy controls $(2,24-27)$. It has been suggested that the (repeated) exposure to early severe stressors increases sensitivity to small stresses in daily life $(2,4,28)$ and that this process of 'behavioural sensitization' is a vulnerability marker for psychosis.

However, until now, only one ESM study (29) has investigated both emotional and symptomatic reactivity to daily life stress in a sample of CHR participants. Compared to psychotic patients and controls, the CHR group experienced greater negative affect (NA) when confronted with stressful activities and social situations, but not after unpleasant events (i.e. emotional stress reactivity). Both the CHR and psychotic patient group showed an increase in psychotic symptoms in response to daily life stressors (i.e. psychotic stress reactivity), in comparison with controls. However, psychotic stress reactivity was comparable across patient groups. Their results suggest that stress reactivity for small daily life stressors and therefore early stress sensitization, occurs before the onset of psychotic disorders and is not just the consequence of a chronic illness.

What is often neglected in stress research is that psychotic experiences in themselves may be an important source of distress. A recent study (30) has shown that intensity of distress related to subclinical symptoms was related to transition risk. Furthermore, ESM studies with psychotic patients have reported that psychotic symptoms are associated with distress and an increase in NA (31-33). This may be particularly true for CHR patients, for whom these experiences are new.

\section{Aims of the study}

Our aim was to examine (i) whether emotional reactivity to stress differs in clinical high risk patients, chronic psychotic patients and healthy controls, (ii) whether psychotic reactivity to stress differs in clinical high risk patients vs. chronic psychotic patients and (iii) whether psychotic symptoms in itself are increasing negative affect in both patient groups. 


\section{Methods}

Sample

The sample consisted of 27 patients who were diagnosed with a non-affective psychotic disorder, 27 participants at CHR for psychosis and 27 healthy controls. Participants in the CHR group were between 18 and 45 years of age and had at least one of the following: (i) attenuated positive symptoms; (ii) brief limited intermittent psychotic symptoms (BLIPS), both assessed with the Structured Interview for Prodromal Symptoms (SIPS; 34); (iii) presence of at least two basic symptoms (e.g. subtle thought and speech disturbances) assessed with the Schizophrenia Prediction Instrument, Adult version (SPI-A; 35); (iv) a significant drop in functioning $(30 \%$ or more on the Global Assessment of Functioning (GAF) Scale for at least 1 month within the last year) in combination with genetic risk; or (v) a significant drop in functioning plus a diagnosis of schizotypal personality disorder. Momentary assessment data for the CHR group were collected in an add-on study of the 'PREVENT' project (for more details see 36), a large German multisite early recognition and intervention in psychosis project. CHR participants who took part in PREVENT were randomly assigned to cognitive behavioural therapy, treatment with Aripiprazole (AbilifyC) and medical management or placebo plus medical management. As the study is not finished yet, disclosure of the assignments of our participants is not yet possible. ESM data collection was started directly after inclusion in the PREVENT.

Controls between the ages of 18 and 45 years were recruited by advertisements at the University of Bonn and other public buildings in Bonn. The Structured Clinical Interview for DSM-IV axis I disorders (SCID-I; 37) was used to assess axis I disorders in the CHR group and to exclude any participants with a psychiatric disorder from the control group. Control participants were also excluded in case of a family history of psychotic disorder.

The ESM data of the psychotic patients were gathered as part of an add-on study to the Genetic Risk and Outcome of Psychosis (GROUP) study (38), which investigated risk and protective factors for psychosis. Patients were recruited through inand out-patient mental health facilities in the southern part of the Netherlands and (the Dutch speaking part of) Belgium. Inclusion criteria for the patient group were age 16-60 years and a diagnosis of schizophrenia or schizoaffective disorder as assessed with the CASH (Comprehensive Assessment of Symptoms and History; 39).
Patients with substance-related psychosis and psychosis with a known organic cause were excluded. For the current analyses, only those patients with minimum illness duration of 5 years since their first psychotic episode were selected. Exclusion criteria for all three groups were a history of brain disease or head injury with loss of consciousness. All participants gave written informed consent, conforming to local ethics committee guidelines.

The experience sampling method

The Experience Sampling Method (ESM) is a within-day, momentary self-assessment technique (40, 41). Participants received a digital wristwatch, and self-assessment forms collected in a booklet for each day. Ten times a day on six consecutive days, the watch emitted a signal (beep) at unpredictable moments between 7:30 a.m. and 10:30 p.m. After each beep, participants were asked to immediately report their thoughts, mood, symptoms, current context (e.g. their location, social company, activities) and subjective appraisals of the current situation. All self-assessments were rated on seven-point Likert scales. To ensure reliability of the completed reports, participants also recorded the time of completion of the report, which was compared with the time at which the watch had emitted a signal. All reports completed more than 15 min after the signal were excluded from the analyses, as previous work (42) has shown that reports completed after this interval are less reliable and consequently less valid. Participants with less than 20 valid reports (out of 60) were excluded from the analysis.

\section{Assessment of mood}

Negative affect was assessed at each beep with six mood-related adjectives (down, guilty, insecure, lonely, anxious, irritated) rated on seven-point Likert scales $(1=$ not at all, $7=$ very $)$. However, detailed factor analyses based on the ESM data collected in several studies conducted in our department have shown that the 'down' and 'irritated' variables have high negative cross-loadings on the positive affect measure (T. Lataster, personal communication, 43). Therefore, mean scores on the items 'guilty', 'insecure', 'lonely' and 'anxious' were used as a measure of NA in the analyses.

\section{Assessment of momentary psychotic symptoms}

Psychotic symptomatology was assessed at each beep with seven symptom-related items. Hallucinations were asked directly ('I hear voices' and 'I see 
things that are not really there'), while the presence of delusions was assessed indirectly by items that include aspects of mental states that are directly associated with delusions in schizophrenia $(44,45)$. These were 'I cannot get these thoughts out of my head'; 'I feel suspicious'; 'I feel unreal' and 'My thoughts are influenced by others'. The item 'I am afraid I will lose control' is related to psychosis in general.

\section{Assessment of momentary stress}

Stress was conceptualized as the subjectively appraised stressfulness of distinctive (social) events and minor disturbances that continually happen in the natural flow of daily life. Three different stress measures were computed. For Activity-related stress, the question 'What are you doing?' served as a starting point. Subsequently, three questions (i.e. 'I would rather do something else'; 'This is difficult for me' and 'I can do this well', reverse coded) were scored on a seven-point Likert scale (1-7) and were combined into a mean activityrelated stress variable. Event-related stress was based on the question 'What was the most important event since the last beep?' Participants subsequently scored how pleasant/unpleasant the event was on a bipolar scale ( -3 very unpleasant, 0 neutral, +3 very pleasant). Positive events (scores 1,2 and 3) were recorded to zero, and negative scores multiplied by -1 (i.e. higher scores now reflect higher stress/unpleasantness levels) for the eventrelated stress variable. For Social stress, participants were asked to indicate whether they were in the company of others or alone. If they were in company of one or more persons, they were asked to rate the item 'I would prefer to be alone' (1-7). This score was used as the social stress variable.

\section{Analyses}

Groups were compared with respect to continuously measured baseline characteristics by means of ANOVAs. Chi-square tests were used to compare groups with respect to categorical variables. Group comparisons (ANOVAs) were also performed to test whether the average levels of NA, momentary psychotic symptoms as well as stress related to unpleasant activities, events and social situations differed between the psychotic patients, CHR patients and controls.

For the further analyses, we used multivariate multilevel models $(46,47)$, an extension of standard hierarchical linear models when analysing multiple (correlated) outcomes. In particular, a certain pair of variables (e.g. activity stress and
NA) was repeatedly measured within participants using ESM, as described earlier. For each participant, we therefore had up to 60 (measurement occasions) $\times 2 \quad$ (outcomes) $=120$ observations available. The data therefore conformed to a three-level structure, with the two outcomes nested within measurement occasions ('beeps'), which in turn were nested within participants. To model the association between the two outcomes at the participant and at the beep level, we used a linear mixed-effects model with two correlated random effects at the participant level (corresponding to two dummy variables indicating whether a particular row of data corresponded to outcome 1 or outcome 2) and with correlated residuals at the beep level. The variance-covariance matrices of the random effects at the participant level and the residuals at the beep level were allowed to be fully unstructured. Age and gender and their interactions with the dummy variables were included as covariates in the model, as previous ESM research has shown a heightened affective stress response in female compared to male psychotic patients (48) and participants in the psychotic patient group were older than those in the CHR and control groups. As it can be hypothesized that the association between stress and psychotic symptoms is influenced by low mood (i.e. high NA), we ran the models testing the association between stressors and momentary psychotic symptoms both with and without NA and its interactions with the dummy variables as covariates.

Models were fitted separately in each of the three groups. To test whether the degree of association (i.e. correlation) between two outcomes differed between the groups at the beep level, we extracted the estimated correlations with their corresponding standard errors and then conducted Wald-type tests (i.e. $z=\left(\hat{\rho}_{1}-\hat{\rho}_{2}\right) / \sqrt{\operatorname{SE}\left[\hat{\rho}_{1}\right]^{2}+\operatorname{SE}\left[\hat{\rho}_{2}\right]^{2}}$, where $\hat{\rho}_{1}$ and $\hat{\rho}_{2}$ are the beep-level correlations for the first and second group, respectively, and $\mathrm{SE}\left[\hat{\rho}_{1}\right]$ and $\mathrm{SE}\left[\hat{\rho}_{2}\right]$ denote the corresponding standard errors). The models were fitted with restricted maximum likelihood (REML) estimation using the mixed routine in Stata 13.1 (49).

We used this method to investigate whether (i) the association strength between stress (activityrelated, event-related and social) and NA differed between the CHR and psychotic patient groups as well as the CHR and healthy control groups; (ii) the association strength between stress and momentary psychotic symptoms differed between the CHR and psychotic patients groups, once in the standard model and once in the model with NA added as a covariate; and (iii) the association 
strength between momentary psychotic symptoms and negative emotions (symptoms as stressor) differed between CHR and psychotic patients.

\section{Results}

\section{Participants and descriptive statistics}

The total sample consisted of 27 healthy controls, 27 CHR patients and 27 psychotic patients. Inclusion criteria were incomplete for three CHR participants and were therefore excluded. After dropping the invalid beeps (i.e. filled out more than 15 min after the actual beep) and selecting those participants who had filled out a minimum of 20 valid beeps, 26 healthy controls, 22 CHR and 24 patients remained, with a total number of 2950 observations and a mean number of 41.0 $(\mathrm{SD}=9.8)$ beeps

Demographic and clinical characteristics are shown in Table 1 . The patients were significantly older than both the CHR patients and controls ( $F$ $(2,69)=17.01, \quad P<0.001, \quad$ Tukey-Kramer: patients $>$ CHR, controls, $P<0.001)$. Gender $\left(\chi^{2}=1.61, \quad P=0.45\right) \quad$ and education level $\left(\chi^{2}=6.13, P=0.41\right)$ were similarly distributed over the three groups.

The groups did not differ on the mean number of valid beeps (see Table 2). The CHR and psychotic patient groups reported significantly more NA and momentary psychotic symptoms when compared with the controls (see Table 2 for all

Table 1. Sociodemographic and clinical characteristics

\begin{tabular}{|c|c|c|c|}
\hline & Psychotic patients $(n=24)$ & Clinical high risk patients ( $n=22$ ) & Control subjects $(n=26)$ \\
\hline \multicolumn{4}{|l|}{ Demographic variables } \\
\hline Age $^{*} \uparrow$, mean (SD), range & 33.9 (8.8), 20-50 & $25.2(5.0), 19-38$ & $24.5(3.6), 19-33$ \\
\hline Gender (m/f) & $15 / 9$ & $17 / 5$ & $16 / 10$ \\
\hline \multicolumn{4}{|l|}{ Civil status, $n(\%)$} \\
\hline Not married & $15(63)$ & $19(86)$ & $21(81)$ \\
\hline Married/living together & $6(25)$ & $1(5)$ & $4(15)$ \\
\hline Divorced & $3(12)$ & & \\
\hline Widowhood & & & $1(4)$ \\
\hline Missing & & $2(9)$ & \\
\hline \multicolumn{4}{|l|}{ Work situation, $n(\%)$} \\
\hline Household & $1(4)$ & & \\
\hline School/education & $1(4)$ & $14(64)$ & $17(65)$ \\
\hline Regular work & $12(50)$ & $3(14)$ & $8(31)$ \\
\hline Structured work & $3(13)$ & & \\
\hline Non-structured activities & $5(21)$ & $4(18)$ & \\
\hline Other & & & $1(4)$ \\
\hline Missing & $2(8)$ & $1(4)$ & \\
\hline \multicolumn{4}{|l|}{ Education level, $n(\%)$} \\
\hline No education & & $1(5)$ & \\
\hline Secondary school & $17(71)$ & $15(68)$ & $22(85)$ \\
\hline Higher education & $7(29)$ & $5(23)$ & $4(15)$ \\
\hline Missing & & $1(5)$ & \\
\hline \multicolumn{4}{|l|}{ Clinical variables } \\
\hline \multicolumn{4}{|l|}{ DSM-IV axis I diagnosis $(n)$} \\
\hline Schizophrenia & 15 & & \\
\hline Schizoaffective disorder & 7 & & \\
\hline Brief psychotic disorder & 1 & & \\
\hline Delusional disorder & 1 & & \\
\hline Major depression & & 7 & \\
\hline Dysthymia & & 1 & \\
\hline Social phobia & & 2 & \\
\hline OCD & & 2 & \\
\hline PTSD & & 1 & \\
\hline Panic disorder & & 1 & \\
\hline Alcohol misuse & & 1 & \\
\hline No diagnosis & & 10 & 26 \\
\hline Psychotic episodes (PE), mean (SD), range & $2.7(1.7), 1-8$ & & \\
\hline IIIness duration, mean $(S D)$, range & $9.6(5.2), 5.0-21.5$ & & \\
\hline Age of first PE, mean (SD), range & $24.3(6.7), 12-41$ & & \\
\hline Antipsychotic medication use $\mathrm{y} / \mathrm{n} /$ ? & $18 / 4 / 2$ & & \\
\hline PANSS-positive symptoms & $1.83(0.77)$ & & \\
\hline
\end{tabular}

*Patients are significantly older than controls $(P<0.001)$.

$\uparrow$ Patients are significantly older than clinical high risk patients $(P<0.001)$. 


\section{van der Steen et al.}

Table 2. Means (standard deviations) and F-test statistics of the number of valid beeps and ESM variables for psychotic patients, CHR patients and controls

\begin{tabular}{|c|c|c|c|c|c|c|}
\hline & \multicolumn{3}{|c|}{ Mean $(S D) \dagger$} & \multirow[b]{2}{*}{$F(\mathrm{df}=2,69)$} & \multirow[b]{2}{*}{$P$} & \multirow[b]{2}{*}{ Tukey-Kramer末 } \\
\hline & Psychotic patients $(n=24)$ & Clinical high risk patients $(n=22)$ & Control subjects $(n=26)$ & & & \\
\hline Valid beeps & 41.5 (10.5), range $20-60$ & $38.5(9.7)$, range $21-58$ & 42.7 (9.3), range 23-56 & 1.14 & 0.33 & \\
\hline Activity-related stress & $2.53(0.87)$ & $2.80(0.69)$ & $2.28(0.53)$ & 3.22 & 0.046 & $3<2^{*}$ \\
\hline Event-related stress & $0.21(0.43)$ & $0.27(0.25)$ & $0.15(0.11)$ & 1.00 & 0.37 & \\
\hline Social stress & $1.66(0.75)$ & $2.59(1.27)$ & $1.54(0.60)$ & 9.42 & 0.0002 & $1<2^{* *} \& 3<2^{* * *}$ \\
\hline NA & $1.95(0.98)$ & $2.02(0.84)$ & $1.17(0.21)$ & 10.11 & 0.0001 & $3<1^{* *}, 2^{* *}$ \\
\hline MPS & $1.67(0.71)$ & $1.68(0.61)$ & $1.07(0.17)$ & 10.38 & 0.0001 & $3<1^{* *}, 2^{* *}$ \\
\hline
\end{tabular}

NA, negative affect; MPS, momentary psychotic symptoms. $* P \leq 0.05, * * P \leq 0.01, * * * P \leq 0.001$

$\dagger$ For each subject, a mean was calculated over all reports, and the mean per subject was additionally aggregated over the group to obtain the group mean (SD).

$\$$ 1. Psychotic patients; 2. CHR; 3. controls.

results). The CHR group, but not the patient group reported significantly more activity-related and social stress in comparison to controls. Furthermore, social stress was significantly higher in CHR patients compared to psychotic patients, while the psychotic patients did not differ from controls. No other significant differences were observed.

Is the association between stress and negative affect different in the three groups?

The results of the multivariate multilevel models showed the correlation coefficients between NA and activity-related, event-related and social stress all to be positive, for the psychotic patient group, CHR group and control group (range 0.11-0.28, see Table 3). For NA and activity-related stress, the association was significantly stronger in the CHR group compared to both the psychotic patient group $(Z=-2.67, P=0.008)$ as well as the healthy controls $(Z=3.68, P=0.0002)$, as displayed in Fig. 1. The associations between NA and event-related stress and NA and social stress were not significantly different in the three groups.

Is the association between stress and momentary symptoms different for Clinical High Risk vs. psychotic patients?

The correlation coefficients between momentary psychotic symptoms and activity-related, eventrelated and social stress were positive for both the CHR patients and psychotic patients (range 0.080.24 , see Table 3 ). For momentary psychotic symptoms and activity-related stress, the association was significantly stronger in the CHR group compared to the psychotic patient group $(Z=-2.29, \quad P=0.02)$. While the association between symptoms and event-related stress was stronger in the CHR group as compared to psychotic patients, it did not reach statistical significance $(Z=-1.66, P=0.10)$. No group differences

Table 3. Multivariate multilevel model correlations at beep level between the stress variables, negative affect and momentary psychotic experiences, controlled for age and gender.

\begin{tabular}{|c|c|c|c|c|c|c|c|c|c|c|c|c|c|}
\hline \multirow[b]{3}{*}{ Association } & \multirow{2}{*}{\multicolumn{3}{|c|}{ Psychotic patients }} & \multirow{2}{*}{\multicolumn{3}{|c|}{ Clinical high risk patients }} & \multirow{2}{*}{\multicolumn{3}{|c|}{ Control subjects }} & \multicolumn{4}{|c|}{ Group comparisons Wald test $\dagger$} \\
\hline & & & & & & & & & & \multicolumn{2}{|c|}{1 vs. 2 (ref) } & \multicolumn{2}{|c|}{2 vs. 3 (ref) } \\
\hline & $\mathrm{CC}$ & SE & $95 \% \mathrm{Cl}$ & $\mathrm{CC}$ & SE & $95 \% \mathrm{Cl}$ & CC & SE & $95 \% \mathrm{Cl}$ & $Z$ & $P$ & Z & $P$ \\
\hline AS \& NA & 0.16 & 0.03 & $0.09-0.22$ & 0.28 & 0.03 & $0.21-0.34$ & 0.11 & 0.03 & $0.05-0.17$ & -2.67 & 0.008 & 3.68 & $<0.001$ \\
\hline$E S \& N A$ & 0.15 & 0.03 & $0.09-0.21$ & 0.16 & 0.03 & $0.09-0.23$ & 0.12 & 0.03 & $0.06-0.18$ & -0.25 & 0.80 & 1.00 & 0.32 \\
\hline SS \& NA & 0.20 & 0.04 & $0.13-0.27$ & 0.16 & 0.05 & $0.07-0.25$ & 0.15 & 0.04 & $0.08-0.23$ & 0.74 & 0.46 & 0.08 & 0.93 \\
\hline AS \& MPS & 0.14 & 0.03 & $0.07-0.20$ & 0.24 & 0.03 & $0.17-0.30$ & & & & -2.29 & 0.02 & & \\
\hline AS \& MPS* & 0.09 & 0.03 & $0.03-0.15$ & 0.11 & 0.03 & $0.05-0.18$ & & & & -0.53 & 0.60 & & \\
\hline ES \& MPS & 0.08 & 0.03 & $0.01-0.14$ & 0.16 & 0.04 & $0.09-0.23$ & & & & -1.66 & 0.10 & & \\
\hline ES \& MPS* & 0.03 & 0.03 & $-0.03-0.10$ & 0.08 & 0.04 & $0.01-0.15$ & & & & -1.04 & 0.30 & & \\
\hline SS \& MPS & 0.15 & 0.04 & $0.07-0.23$ & 0.19 & 0.04 & $0.10-0.27$ & & & & -0.60 & 0.55 & & \\
\hline SS \& MPS* & 0.09 & 0.04 & $0.01-0.17$ & 0.12 & 0.05 & $0.03-0.21$ & & & & -0.47 & 0.64 & & \\
\hline NA \& MPS & 0.33 & 0.03 & $0.27-0.38$ & 0.53 & 0.03 & $0.48-0.58$ & & & & -5.42 & $<0.001$ & & \\
\hline
\end{tabular}

CC, correlation coefficient; SE, standard error; 95\% Cl, 95\% confidence interval; NA, negative affect; MPS, momentary psychotic symptoms; AS, activity-related stress; ES, event-related stress; SS, social stress.

${ }^{*}$ Results of models with NA included as a covariate.

$\dagger$ 1. Psychotic patients; 2. CHR; 3. controls. 


\section{Stress, affective and psychotic symptoms in CHR}

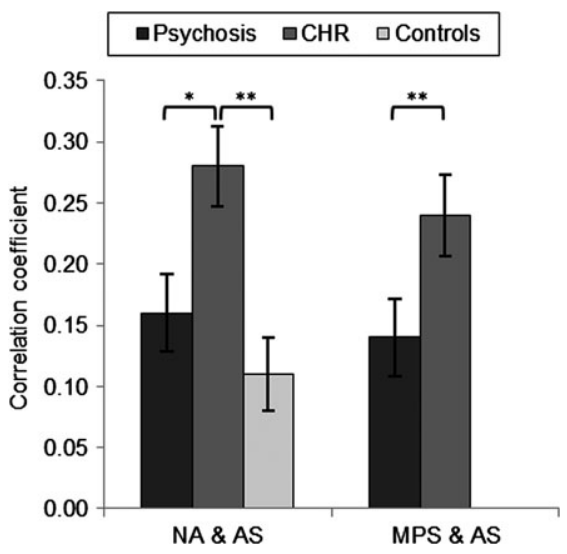

Fig. 1. Left: Correlation coefficients between negative affect (NA) and activity-related stress (AS) per group. Right: Correlation coefficients between momentary psychotic symptoms (MPS) and activity-related stress per group. ${ }^{*} P \leq 0.01$, $* * P \leq 0.001$

were detected for symptoms and social stress. In the additional analyses where NA was added as a covariate in the models, the association between activity-related stress and symptoms was no longer significantly different between groups $(Z=-0.53$, $P=0.60)$, as were none of the other comparisons.

Are momentary psychotic symptoms more emotionally distressing for clinical high risk vs. psychotic patients?

Positive associations between momentary psychotic experiences and NA were found for the CHR and psychotic patient groups (see Table 3). Group comparison showed the association to be significantly larger in the CHR group than in the psychotic patients group $(Z=-5.42, P<0.001)$, as displayed in Fig. 1.

\section{Discussion}

This study investigated emotional and psychotic reactivity to daily life stress in those at risk for a psychotic disorder compared to chronic psychotic patients and healthy controls. As hypothesized, our results showed increased emotional stress reactivity, particularly related to activities, to be associated with psychosis, mainly at the early stages of illness. Contrary to our hypothesis, psychotic reactivity in response to unpleasant activities was increased in CHR compared to chronic psychotic patients. This suggests that emotional and psychotic stress sensitization occurs prior to the development of a full-blown psychotic state. Furthermore, as hypothesized, CHR patients experienced the psychotic symptoms as more distressing compared to chronic patients.

\section{Emotional and psychotic stress reactivity}

Our results of increased emotional stress reactivity in CHR compared to chronic patients are replicating the findings of Palmier-Claus et al. (29). Furthermore, results are in line with studies in CHR samples using questionnaires showing higher psychosocial stress sensitivity in CHR participants compared to controls (23), reduced tolerance to normal stress (20), higher self-reported distress in response to life events $(19,22)$ as well as to daily life stressors $(15,50)$, especially for those reporting life events to be more distressing, suggestive of stress sensitization (19). Psychotic stress reactivity, however, was stronger in the CHR patients compared to psychotic patients, contrary to our hypothesis based on the findings of Palmier-Claus et al. (29). One possible explanation for this difference may be related to selection of the psychotic patients. We specifically selected psychotic patients with an illness duration of at least 5 years, to compare our CHR group with chronic patients. The patient sample of Palmier-Claus et al. (29) is likely more mixed with both recent onset and more chronic patients, as they did not provide specific inclusion criteria in that regard. This is reflected in the difference in mean illness duration, with our sample having a mean illness duration of 9.6 $(\mathrm{SD}=5.2)$ years compared to $6.5(\mathrm{SD}=8.2)$ years reported in their paper. Psychotic stress reactivity may thus be more characteristic of the early psychotic phase and becoming less prominent when illness duration progresses.

There are several other possible explanations for our findings of heightened emotional and psychotic stress reactivity in CHR patients compared to the chronic psychotic patients. First, the CHR may experience more severe stressors or these may occur more often than those experienced by the patient group, as was indeed confirmed by our findings of increased activity and social stress in this group. As high levels of social anxiety have been reported to characterize help-seeking CHR patients $(51,52)$, more exposure to social activities in our CHR group helps to explain the difference with the psychotic patients, who have possibly adjusted their lives in order to avoid stressful (social) situations. Alternatively, less exposure to activities, events and social situations might be a consequence of more negative symptoms (53), which has been related to lower social functioning, work performance and social skills. In accordance with this, a recent study comparing negative symptoms in psychotic and CHR patients (54) reported that psychotic patients differed from CHR patients by reporting less motivation for engagement with 
family and recreational activities. However, as negative symptoms are profound not only in psychotic patients but also in help-seeking CHR patients (55) and the recent study of Cressman et al. (51) showed the level of anhedonia to be comparable to that of psychotic patients, the influence on the reported group difference in exposure to (social) activities is probably limited.

Second, a recent study has reported that CHR patients do not seem to possess the skills to effectively cope with stress in general. Compared to healthy controls, CHR patients used more maladaptive coping strategies (e.g. blaming one's self for the occurrence of the event) and fewer adaptive (e.g. choosing to reinterpret the event in a positive fashion) coping strategies, and the use of these strategies might limit their functioning even further or exacerbate symptoms (56). Furthermore, use of adequate coping strategies like stress reduction has been found to predict an improvement with regard to psychotic symptoms over time (57).

Third, most of our psychotic patients used antipsychotic medication. It could therefore be that antipsychotic medication partly dampens emotional and psychotic stress reactivity, resulting in the difference observed between our patient groups. Some evidence comes from a recent study (58) in which psychotic patients who use antipsychotic medication subjectively reported dampened emotional experience. However, as not all our psychotic patients were using antipsychotic medication and some of the CHR patients have been using medication, use of antipsychotics is unlikely to fully explain the difference in stress reactivity between the groups.

Finally, the results of our sensitivity analyses investigating the influence of low mood on psychotic reactivity underscore the close relationship between stress, symptoms and low mood. When NA was added to the psychotic stress reactivity models, it was no longer significantly higher in the CHR group compared to more chronic patients, suggesting that psychotic stress reactivity is mediated by low mood at the early phases of illness.

\section{Psychotic symptoms and distress}

The current study provided evidence that psychotic symptoms in themselves may be a source of distress, particularly in CHR patients. These symptoms are relatively new for CHR patients, and belief conviction may not have been fully developed. The unknown nature of these symptoms may intensify the levels of distress. Results of a recent study on stigma related to labels and symptoms of CHR also identified subclinical psychotic symptoms in themselves to be a source of distress (59). CHR patients experienced more stigma from symptoms than from the psychosis risk-label, and specifically the 'shame' related to symptoms was associated with depression.

Another possible explanation might be that CHR patients may have received no or limited treatment, either psycho-education or psychological treatment, for these symptoms as ESM assessment started just after identification of CHR status, which may result in less effective coping strategies. A previous ESM study of psychotic patients (33) indeed showed that a greater endorsement of a psychological explanation of delusions and hallucinations was related to less disruption of functioning, less distress and less NA. On the other hand, chronic patients may differ from CHR patients in coping strategies they use to deal with the symptoms. Lardinois et al. (31) showed that psychotic patients who used more non-psychotic coping strategies (i.e. active problem-solving or avoiding, passive illness behaviour and problemavoiding) had more conscious appraisal of distress associated with symptoms than those who adopted a more symptomatic coping strategy, for example following or obeying orders induced by the symptoms or locking oneself in.

\section{Theoretical and clinical implications}

Overall, our findings further support the hypothesis that increased stress reactivity can be viewed as an affective pathway to psychosis (2). They also highlight the important role of distress, represented in this study as an increase in NA, with the emergence of psychotic symptoms. The results suggest that CHR patients may get caught in a downward spiral of feeling distressed by their psychotic symptoms, which may in turn increase the intensity of psychotic symptoms.

Our findings underscore the need for early intervention in CHR patients to interrupt this vicious cycle. Decreasing stress reactivity as well as decreasing the distress associated with the psychotic symptoms is relevant in this respect. The newest generation of cognitive behavioural therapies (CBTs) puts high emphasis on the context (hence the name 'contextual CBT'). Stress reduction techniques, which incorporate elements of Mindfulness or Acceptance and Commitment Therapy, may be an effective treatment strategy (for a review see 60). Given the observation that CHR patients coping strategies are often ineffective and can enhance symptoms (56) and use of adequate strategies have been found to be predictive of improvement in psychotic symptoms (57), 
interventions that help CHR patients to develop and apply adequate coping strategies are also likely to be effective.

\section{Limitations}

The results should be viewed in the light of several methodological issues. First, as with all ESM studies, measurements are based on subjective reports. Therefore, it can be argued that the results are not psychometrically precise. However, although subjective reports are considered less reliable (e.g. do all participants interpret or answer the questions identically?), previous research indicates that subjective reports can be valid and are important to understand the changes in symptoms (61).

Second, the items used to assess momentary psychosis are relatively broad, as items were used that participants could self-report about. However, one could question whether they truly reflect a psychotic state. For example, 'I cannot get these thoughts out of my head' may equally reflect anxiety or depression. A principal component analysis on the psychosis items resulted in two factors, one factor representing hallucinations (the two hallucination items) and all the other items loading equally on a second factor, which would then reflect delusions. However, does this second factor truly reflect delusions? All items scored equally strong on the factor delusions including 'I feel suspicious', or 'My thoughts are influenced by others', suggesting that the composite score most likely represents delusions. Furthermore, previous studies from our group showed that the psychosis score as used in the current paper had concurrent validity (as the ESM psychosis scores were significantly correlated with the score on the positive items but not the negative items of the PANSS) and convergent validity using the known-groups technique (as it distinguished patients from relatives and controls; 26). This supports that the composite score of all items does reflect psychosis. However, the psychosis items could be strengthened in future research for example using focus groups with people who have experienced psychosis.

Third, the study was cross-sectional and therefore, no direct causality can be inferred from these results. Furthermore, the possibility of reverse causality cannot be excluded. There is a possibility that increased NA or increased levels of psychotic symptoms influence the subjective appraisal of the environment or that increased NA causes psychotic symptoms to be experienced as more intense. However, as was suggested previously, the overall effect would still be for the individual to experience psychosis associated with an environmental event (26).

Fourth, the possible influence of medication use to the examined associations could not be tested in the current study, as CHR medication use was not yet available. While at present disclosure of treatment is not yet available, CHR participants did receive either cognitive behavioural therapy, treatment with Aripiprazole (Abilify $($ ) ) plus medical management or a placebo plus medical management. The majority of psychotic patients used antipsychotic medication at the time of testing. Future studies are needed to examine the effect of medication use properly by comparing patients groups with and without antipsychotic medication use.

\section{Acknowledgements}

This work was supported by the ERC consolidator grant (I.MG., ERC-2012-StG, project 309767 - INTERACT); the German Research Foundation (DFG, grant KL 970/7-1); and by the 'Op De Pedalen' Fund (funding the graduate position of Y. van der Steen). The authors thank research coordinators Truda Driesen and Debora Op 't Eijnde for their work on this project.

\section{Declaration of interest}

None.

\section{References}

1. Corcoran CM, Walker E, Huot R et al. The stress cascade and schizophrenia: etiology and onset. Schizophr Bull 2003;29:671-692.

2. Myin-Germeys I, van Os J. Stress-reactivity in psychosis: evidence for an affective pathway to psychosis. Clin Psychol Rev 2007;27:409-424.

3. Phillips LJ, Francey SM, Edwards J, McMurray N. Stress and psychosis: towards the development of new models of investigation. Clin Psychol Rev 2007;27:307-317.

4. van Winkel R, Stefanis NC, Myin-Germeys I. Psychosocial stress and psychosis. A review of the neurobiological mechanisms and the evidence for gene-stress interaction. Schizophr Bull 2008;34:1095-1105.

5. Zubin J, Spring B. Vulnerability - a new view of schizophrenia. J Abnorm Psychol 1977;86:103-126.

6. Beards S, Gayer-Anderson C, Borges S, Dewey ME, Fisher HL, Morgan C. Life events and psychosis: a review and meta-analysis. Schizophr Bull 2013;39:740-747.

7. Varese F, SMeets F, Drukker M et al. Childhood adversities increase the risk of psychosis: a meta-analysis of patient-control, prospective- and cross-sectional cohort studies. Schizophr Bull 2012;38:661-671.

8. Malla AK, Cortese L, Shaw TS, Ginsberg B. Life events and relapse in schizophrenia. A one year prospective study. Soc Psychiatry Psychiatr Epidemiol 1990;25:221224.

9. Norman RM, Malla AK. A prospective study of daily stressors and symptomatology in schizophrenic patients. Soc Psychiatry Psychiatr Epidemiol 1994;29:244-249. 


\section{van der Steen et al.}

10. Yung AR, Yung AR, Pan Yuen H et al. Mapping the onset of psychosis: the comprehensive assessment of at-risk mental states. Aust N Z J Psychiatry 2005;39:964-971.

11. Miller TJ, McGlashan TH, Rosen JL et al. Prospective diagnosis of the initial prodrome for schizophrenia based on the structured interview for prodromal syndromes: preliminary evidence of interrater reliability and predictive validity. Am J Psychiatry 2002;159:863-865.

12. Addington J, Stowkowy J, Cadenhead KS et al. Early traumatic experiences in those at clinical high risk for psychosis. Early Intervent Psychiatry 2013;7:300-305.

13. Bechdolf A, Thompson A, Nelson B et al. Experience of trauma and conversion to psychosis in an ultra-high-risk (prodromal) group. Acta Psychiatr Scand 2010;121:377384.

14. Sahin S, Yuksel C, Guler J et al. The history of childhood trauma among individuals with ultra high risk for psychosis is as common as among patients with first-episode schizophrenia. Early Intervent Psychiatry 2013;7: 414-420.

15. Tessner KD, Mittal V, Walker EF. Longitudinal study of stressful life events and daily stressors among adolescents at high risk for psychotic disorders. Schizophr Bull 2011;37:432-441.

16. Thompson JL, Kelly M, Kimhy D et al. Childhood trauma and prodromal symptoms among individuals at clinical high risk for psychosis. Schizophr Res 2009;108:176-181.

17. Velthorst E, Nelson B, O’Connor K et al. History of trauma and the association with baseline symptoms in an Ultra-High Risk for psychosis cohort. Psychiatry Res 2013;210:75-81.

18. Tikka M, Luutonen S, Ilonen T et al. Childhood trauma and premorbid adjustment among individuals at clinical high risk for psychosis and normal control subjects. Early Intervent Psychiatry 2013;7:51-57.

19. Trotman HD, Holtzman CW, Walker EF et al. Stress exposure and sensitivity in the clinical high-risk syndrome: initial findings from the North American Prodrome Longitudinal Study (NAPLS). Schizophr Res 2014;160:104109.

20. Devylder Je, Ben-David S, Schobel SA, Kimhy D, MalaSPINA D, CORCORAN CM. Temporal association of stress sensitivity and symptoms in individuals at clinical high risk for psychosis. Psychol Med 2013;43:259-568.

21. Miller P, Lawrie SM, Hodges A, Clafferty R, Cosway R, Johnstone EC. Genetic liability, illicit drug use, life stress and psychotic symptoms: preliminary findings from the Edinburgh study of people at high risk for schizophrenia. Soc Psychiatry Psychiatr Epidemiol 2001;36:338-342.

22. Phillips LJ, Edwards J, McMurray N, Francey S. Comparison of experiences of stress and coping between young people at risk of psychosis and a non-clinical cohort. Behav Cogn Psychother 2012;40:69-88.

23. Pruessner M, Iyer SN, Faridi K, Joober R, Malla AK. Stress and protective factors in individuals at ultra-high risk for psychosis, first episode psychosis and healthy controls. Schizophr Res 2011;129:29-35.

24. Lardinois M, Lataster T, Mengelers R, van Os J, MyinGermeYs I. Childhood trauma and increased stress sensitivity in psychosis. Acta Psychiatr Scand 2011;123:28-35.

25. Lataster $\mathrm{T}, \mathrm{Wichers} \mathbf{M}, \mathrm{J}_{\mathrm{Acobs}} \mathrm{N}$ et al. Does reactivity to stress cosegregate with subclinical psychosis? A general population twin study. Acta Psychiatr Scand 2009;119:4553.

26. Myin-Germeys I, Delespaul P, van Os J. Behavioural sensitization to daily life stress in psychosis. Psychol Med 2005;35:733-741.
27. Myin-Germeys I, van Os J, Schwartz Je, Stone AA, DeleSPAUl P. Emotional reactivity to daily life stress in psychosis. Arch Gen Psychiatry 2001b;58:1137-1144.

28. Collip D, Myin-Germeys I, van Os J. Does the concept of "sensitization" provide a plausible mechanism for the putative link between the environment and schizophrenia? Schizophr Bull 2008;34:220-225.

29. Palmier-Claus Je, Dunn G, Lewis SW. Emotional and symptomatic reactivity to stress in individuals at ultrahigh risk of developing psychosis. Psychol Med 2012;42:1003-1012.

30. Rapado-Castro M, McGorry PD, Yung A, Calvo A, Nelson B. Sources of clinical distress in young people at ultra high risk of psychosis. Schizophr Res 2015;165:15-21.

31. Lardinois M, Myin-Germeys I, BaK M, Mengelers R, van Os J, Delespaul PAEG. The dynamics of symptomatic and non-symptomatic coping with psychotic symptoms in the flow of daily life. Acta Psychiatr Scand 2007;116:71-75.

32. Myin-Germeys I, Nicolson NA, Delespaul PA. The context of delusional experiences in the daily life of patients with schizophrenia. Psychol Med 2001a;31:489-498.

33. Peters E, Lataster T, Greenwood K et al. Appraisals, psychotic symptoms and affect in daily life. Psychol Med 2012;42:1013-1023.

34. Miller T, McGlashan T, Woods S et al. Symptom assessment in schizophrenic prodromal states. Psychiatr Q 1999;70:273-287.

35. Schultze-Lutter F, Addington J, Ruhrmann S, editors. Schizophrenia Proneness Instument, Adult version (SPIA): Giovanni Fioriti Editore, 2007.

36. Bechdolf A, Muller H, Stutzer $\mathrm{H}$ et al. Rationale and baseline characteristics of PREVENT: a second-generation intervention trial in subjects at-risk (prodromal) of developing first-episode psychosis evaluating cognitive behavior therapy, aripiprazole, and placebo for the prevention of psychosis. Schizophr Bull 2011;37(Suppl 2): S111-S121.

37. Wittchen HU, Fydrich T. Strukturiertes Klinisches Iterview für DSM-IV. Manual zum SKID-I und SKID-II. [Structured Clinical Interview for DSM.IV]. Göttingen: Hogrefe, 1997.

38. Korver N, Quee PJ, Boos HB, Simons CJ, de HaAn L. Genetic Risk and Outcome of Psychosis (GROUP), a multi-site longitudinal cohort study focused on gene-environment interaction: objectives, sample characteristics, recruitment and assessment methods. Int $\mathbf{J}$ Methods Psychiatr Res 2012;21:205-221.

39. Andreasen NC, Flaum M, Arndt S. The Comprehensive Assessment of Symptoms and History (CASH). An instrument for assessing diagnosis and psychopathology. Arch Gen Psychiatry 1992;49:615-623.

40. Csikszentminalyi M, Larson R. Validity and reliability of the experience-sampling method. J Nerv Ment Dis 1987; 175:526-536.

41. Myin-Germeys I, Oorschot M, Collip D, Lataster J, DeleSPaul P, van Os J. Experience sampling research in psychopathology: opening the black box of daily life. Psychol Med 2009;39:1533-1547.

42. Delespaul P. Assessing schizophrenia in daily life. Maastricht: Universitaire Pers; 1995.

43. Lataster T, Viechtbauer W, Oorschot M et al. Evidence for a two-factor positive and negative affect structure in daily life: presenting the Maastricht Momentary Mood Questionnaire (3MQ). internal communication.

44. APA. Diagnostic and statistical manual of mental disorders (DSM-IV). Washington, DC: American Psychiatric Association; 1994. 
45. Junginger J, Barker S, Coe D. Mood theme and bizarreness of delusions in schizophrenia and mood psychosis. $\mathrm{J}$ Abnorm Psychol 1992;101:287-292.

46. Twisk JWR. Applied multilevel analysis. Cambridge, UK: Cambridge University Press; 2006.

47. SNidders TAB, Bosker RJ. Multilevel analysis: an introduction to basic and advanced multilevel modeling. London: Sage; 1999.

48. Myin-Germeys I, Krabbendam L, Delespaul PA, van Os J. Sex differences in emotional reactivity to daily life stress in psychosis. J Clin Psychiatry 2004;65:805-809.

49. STATACORP. Stata Statistical Software: Release 13. College Station, TX: StataCorp LP, 2013.

50. Cullen AE, Fisher HL, Roberts Re, Pariante CM, Laurens KR. Daily stressors and negative life events in children at elevated risk of developing schizophrenia. Brit J Psychiatry 2014;204:354-360.

51. Cressman VL, Schobel SA, Steinfeld $\mathrm{S}$ et al. Anhedonia in the psychosis risk syndrome: associations with social impairment and basal orbitofrontal cortical activity. Npj Schizophrenia 2015;1:15020.

52. Rietdijk J, Ising HK, Dragt S et al. Depression and social anxiety in help-seeking patients with an ultra-high risk for developing psychosis. Psychiatry Res 2013;209:309-313.

53. Ventura J, Hellemann GS, Thames AD, Koellner V, NuECHTERLEIN KH. Symptoms as mediators of the relationship between neurocognition and functional outcome in schizophrenia: a meta-analysis. Schizophr Res 2009;113: 189-199.
54. Gur RE, March M, Calkins ME et al. Negative symptoms in youths with psychosis spectrum features: complementary scales in relation to neurocognitive performance and function. Schizophr Res 2015;166:322-327.

55. Piskulic D, Addington J, Cadenhead KS et al. Negative symptoms in individuals at clinical high risk of psychosis. Psychiatry Res 2012;196:220-224.

56. Jalbrzikowski M, Sugar CA, Zinberg J, Bachman P, Cannon TD, BeArden CE. Coping styles of individuals at clinical high risk for developing psychosis. Early Intervent Psychiatry 2014;8:68-76.

57. Kommescher M, Wagner M, Putzfeld V et al. Coping as a predictor of treatment outcome in people at clinical high risk of psychosis. Early Intervent Psychiatry 2016;10:1727.

58. Moritz S, Andreou C, Klingberg S, Thoering T, Peters MJV. Assessment of subjective cognitive and emotional effects of antipsychotic drugs. Effect by defect? Neuropharmacology 2013;72:179-186.

59. Yang LH, Link BG, Ben-David $S$ et al. Stigma related to labels and symptoms in individuals at clinical high-risk for psychosis. Schizophr Res 2015;168:9-15.

60. Hayes SC, Villatte M, Levin M, Hildebrandt M. Open, aware, and active: contextual approaches as an emerging trend in the behavioral and cognitive therapies. Annu Rev Clin Psychol 2011;7:141-168.

61. Strauss JS. The person with schizophrenia as a person. II: Approaches to the subjective and complex. Br J Psychiatry Suppl 1994;23:103-107. 